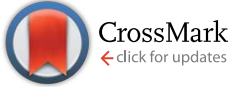

Cite this: RSC Adv., 2017, 7, 11951

Received 18th November 2016 Accepted 13th February 2017

DOI: 10.1039/c6ra26975c

rsc.li/rsc-advances

\section{Towards understanding of laccase-catalysed oxidative oligomerisation of dimeric lignin model compounds $\uparrow$}

\begin{abstract}
B. Ramalingam, ${ }^{\star a}$ B. Sana, ${ }^{\text {J J. Seayad, }}{ }^{\text {a }}$ F. J. Ghadessy ${ }^{\text {b }}$ and M. B. Sullivan ${ }^{c}$
Laccase-catalysed oligomerisation of dimeric $\beta-O-4$ linked lignin model compounds was studied in detail to understand the oligomerisation process by monitoring the reaction progress using high performance liquid chromatography (HPLC) and mass spectroscopy (MS). The initial oxidation intermediates of oligomerisation were isolated for the first time and characterised by spectroscopic methods sucessfully. The experimental observations indicated that $\mathrm{C}_{5}-\mathrm{C}_{5^{\prime}}$ biphenyl linkages, one of the most thermodynamically stable linkages present in the native lignin, are formed exclusively during the early stage of the oligomerisation process. The experimental observations were supported by density functional theory (DFT) calculations of relative free energies of possible products. The $\mathrm{C}_{5}-\mathrm{C}_{5^{\prime}}$ biphenyl tetramer is the thermodynamically more favoured product compared to the $\mathrm{C}_{5}-\mathrm{O}-\mathrm{C}_{4^{\prime}}$ product by a free energy difference of $10.0 \mathrm{kcal} \mathrm{mol}^{-1}$ in water. Among the various linking possibilities for further formation of hexamers, the thermodynamically more stable product with a similar $\mathrm{C}-\mathrm{C}$ linkage is proposed as a plausible structure based on the mass of the hexamer isolated and DFT calculations. The current study demonstrates that laccase catalyzes the oligomerisation more preferentially than oxidative bond cleavage in $\beta-O-4$ linkages and that product formation is likely controlled by the thermodynamic stability of the resultant oligomers.
\end{abstract}

\section{Introduction}

Lignin, the second most abundant natural polymer has attracted much attention as one of the potential feedstocks for the sustainable production of fuels, ${ }^{1}$ chemicals ${ }^{\mathbf{1}, \mathbf{2}}$ and materials. ${ }^{3}$ The lignin polymer mainly consists of phenylpropane units that are bonded through various types of $\mathrm{C}-\mathrm{O}$ and $\mathrm{C}-\mathrm{C}$ linkages, ${ }^{3}$ formed from monolignol such as $p$-coumaryl, coniferyl and sinapyl alcohols (Scheme 1). The polymerisation of monolignols is believed to be catalysed by enzyme cocktails comprising laccase and peroxidases by the preliminary formation of a phenoxy radical followed by uncontrolled radical polymerisation. ${ }^{4}$ Synthetically, laccase, a multi-copper containing metalloenzyme has been used in the polymerisation of phenol and amine containing aromatics ${ }^{5}$ as well as lignin model compounds in the presence of molecular oxygen. The redox potential of the substrates and the nature of substituents on the aromatic ring have been shown to affect the

${ }^{a}$ Organic Chemistry, Institute of Chemical and Engineering Sciences, \#07-01/02 Neuros, 8 Biomedical Grove, Singapore 138 665. E-mail: balamurugan_ramalingam@ices.a-star.edu.sg; Fax: +65 6464 2102; Tel: +65 6799 8529

${ }^{b}$ p53 Laboratory, \#06-04/05 Neuros/Immunos, 8A Biomedical Grove, Singapore 138 648

'Institute of High Performance Computing, 1 Fusionopolis Way, \#16-16 Connexis, Singapore 138632

$\dagger$ Electronic supplementary information (ESI) available: Complete details of GPC, mass and NMR spectra. See DOI: 10.1039/c6ra26975c polymerisation. For instance, in the case of phenols, ${ }^{6}$ naphthols ${ }^{7}$ and methoxy phenols, ${ }^{8}$ enhanced polymerisation rates were observed when a methoxy substituent is present at the orthoposition relative to the phenolic $\mathrm{OH}$ group. The redox potential of substrates was found ${ }^{9}$ to be important in the fungal laccasecatalysed oxidation of various lignin model compounds. The reaction rates of oxidation were studied by monitoring the oxygen consumption and compared with physiochemical properties of monomeric and dimeric model compounds without details on isolated products. In a very recent study, encapsulated laccases were used ${ }^{\mathbf{1 0}}$ as stable catalysts for the oxidative polymerisation of aromatics such as syringic acid, gallic acid, vanillic acid and syringol to obtain lignin-like oligomers with molecular weight ranging between 400-2100 Da. The low molecular oligomeric materials obtained from lignin model compounds, are expected to possess some of the characteristics of the native lignin. Thus, the phenol containing lignin-like oligomers could potentially be utilized as an additive to plastics, ${ }^{11}$ sunscreen lotions, ${ }^{12}$ as antioxidants $^{13}$ and UV absorbers ${ }^{14}$ similar to lignin. The low molecular weight lignin oil was reported ${ }^{\mathbf{1 5}}$ to be a potential lubricant additive for commercial engine oils with better miscibility and compatibility than kraft lignin.

As laccase is one of the key enzymes believed to be responsible for the bio-synthesis and degradation of lignins in nature, it is important to understand the mechanism of laccase catalysed oxidations to explore new applications of laccase catalysis. However, in laccase catalysed oxidations, complexity in 


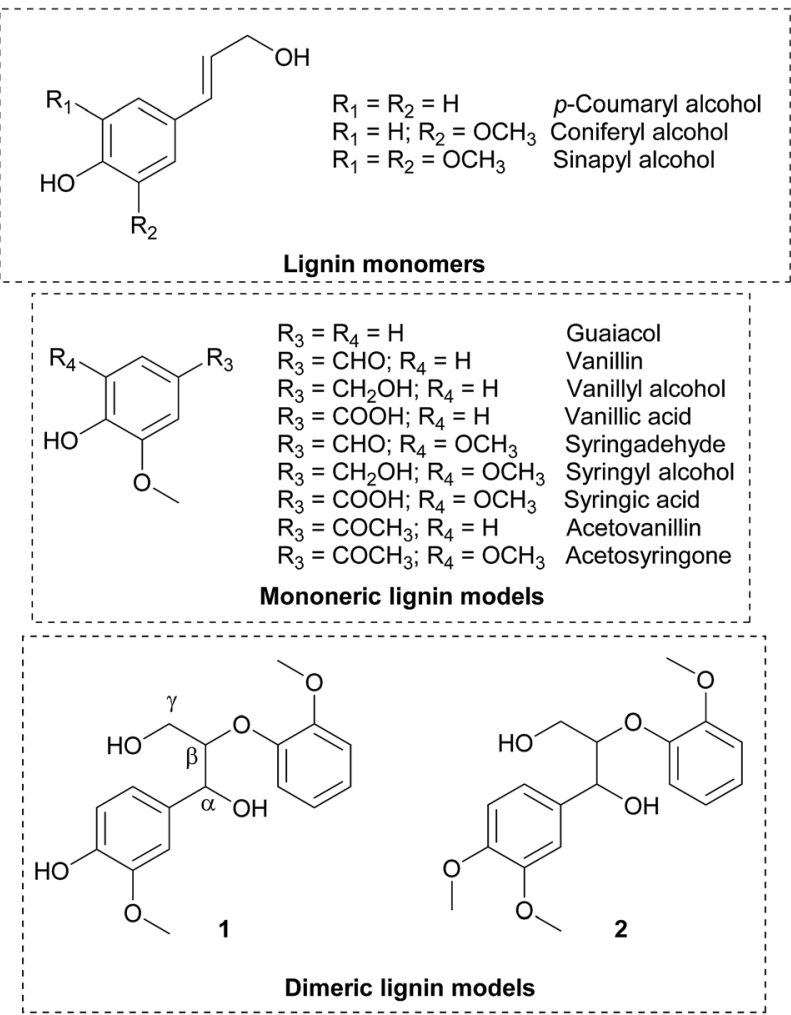

Scheme 1 Chemical structure of lignin monomers and models.

uncontrolled reactions of phenolic radicals and limitations in isolating the initial oxidation products hinder understanding of the lignin polymerisation and depolymerisation processes. In this regard, Lahtinen et al. ${ }^{16}$ have studied the product distribution in the laccase catalysed oxidation of monomeric lignin models such as vanillyl alcohol in detail. Computational evaluation of the oxidation products of vanillyl alcohol and its reaction intermediates indicated that the hydrogen bonding provides an additional stabilising effect for formation of the thermodynamically more stable $\mathrm{C}_{5}-\mathrm{C}_{5^{\prime}}$ linkage. Attempts were also made $^{17}$ to isolate and characterize the products obtained in the fungal laccase catalysed oxidation of guaiacylic and syringylic lignin model compounds. The oxidation of secondary alcohol $\left(\mathrm{C}_{\alpha}\right)$ was observed for syringyl alcohol and syringylic $\beta$-O-4 dimers, while three types of $\mathrm{C}_{5}-\mathrm{C}_{5^{\prime}}$ coupling products were reported for vanillyl alcohol. The Trametes versicolor laccase (TVL) catalysed selective dimerization of lignin model compounds such as vanillin, acetovanillin, methylvanilllate and eugenol was reported recently. ${ }^{18}$ The initial oxidation products were characterised by NMR and all of them were found to contain $\mathrm{C}_{5}-\mathrm{C}_{5^{\prime}}$ linkages. However, no details on linkages present in the higher molecular weight oligomers were reported. Laccase-catalysed oxidative phenolic coupling products with $\mathrm{C}_{5}-\mathrm{C}_{5^{\prime}}$ linkages were reported ${ }^{19}$ for a series of vanillidine derivatives to afford dimeric products in $79-93 \%$ yields.

The polymerisation of lignin model compounds including $\beta$-O-4 linked dimer 1 was reported by Rittstieg et al. using T. hirsuta laccase as a catalyst in the absence ${ }^{20}$ and presence ${ }^{21}$ of 2,2'-azino-bis(3-ethylbenzothiazoline-6-sulphonic acid) (ABTS).
The molecular weight distribution (MWD) 4000 Da was reported in the absence of ABTS, while increase in MWD was observed in presence of ABTS. About $21 \%$ of initially used ABTS was found to present in the resulting polymeric product. Although laccasecatalysed oligomerisation of dimeric lignin model compounds has been reported in the literature, details of the oligomerisation process and linkages present in the oxidation products have not been reported so far. The objective of the current study was to gain insight into the laccase catalysed oxidation process and the mode of linkages present in the initial oxidation products using $\beta-\mathrm{O}-4$ linked dimeric lignin model compounds that are considered close mimetics of native lignin. Unlike the monomeric lignin model compounds, the dimeric model compounds possess $\beta-\mathrm{O}-4$ linkages, the most abundant $(45-60 \%)$ linkage present in native lignin. The structural information gained on the oxidation products of such dimeric model compounds would enable (i) improved knowledge on the role of laccase in enzyme-based lignin polymerisation and depolymerisation processes, (ii) use of the oligomeric materials for specific applications with improved understanding on the linkages present and (iii) to broaden the scope of laccase-catalysed reactions for the greener synthesis of organic molecules in a more sustainable manner.

\section{Results and discussion}

In this study, the oxidation of $\beta-\mathrm{O}-4$ linked dimeric lignin model compounds 1-(4-hydroxy-3-methoxyphenyl)-2(2-methoxy phenoxy)-propane-1,3-diol (1) and 1-(3,4-dimethoxyphenyl)-2(2methoxyphenoxy)-propane-1,3-diol (2) were investigated adopting a similar reaction protocol reported by Rittstieg et al. ${ }^{20}$ Commercially available laccases from Trametes versicolor laccase (TVL), Rhus vernicifera laccase (RVL) and Pleurotus ostreatus laccase (POL) were used as the oxidation catalysts in the current study. Compounds 1 and 2 were independently taken in sodium acetate buffer ( $\mathrm{pH} \sim 5.2)$ under oxygen atmosphere and stirred at room temperature for 3 hours with 20 units per $\mathrm{mL}$ of TVL. A pale brown precipitate formed from the flask containing compound 1 was collected and found to be soluble in common organic solvents such as acetone, ethyl acetate and chloroform. Preliminary analysis by nuclear magnetic resonance (NMR) spectra indicated the complete disappearance of compound $\mathbf{1}$ and possible formation of oligomeric species. Analysis of the precipitate obtained from compound 1 by gel permeation chromatography (GPC) indicated the formation of higher molecular weight compounds with average molecular weight $\left(M_{\mathrm{w}}\right)$ of $2120 \mathrm{Da}$ and polydispersity $\left(M_{\mathrm{w}} / M_{\mathrm{n}}\right)$ of 1.1 (Fig. 1). A molecular weight distribution (MWD) up to $4000 \mathrm{Da}$ was reported ${ }^{20}$ for the polymerisation of compound 1 using T. hirsuta laccase. The observed difference (2120 vs. $4000 \mathrm{Da})$ in MWD might be due to the variance in source and concentration of the laccase and methods used in molecular weight determination. POL also promoted the oligomerisation of $\mathbf{1}$ as that of TVL and led to the formation of oligomers with similar $\operatorname{MWD}\left(M_{\mathrm{n}}=\right.$ $2095 \mathrm{Da} ; M_{\mathrm{w}}=2165 \mathrm{Da} ; M_{\mathrm{w}} / M_{\mathrm{n}}=1.0$, Fig. S1, ESI $\dagger$ ). Treatment of compound 1 with RVL did not promote any oxidation products and the starting material remained unreacted (Fig. 3) as observed by NMR and HPLC. Treatment of compound 2 with TVL, RVL and 


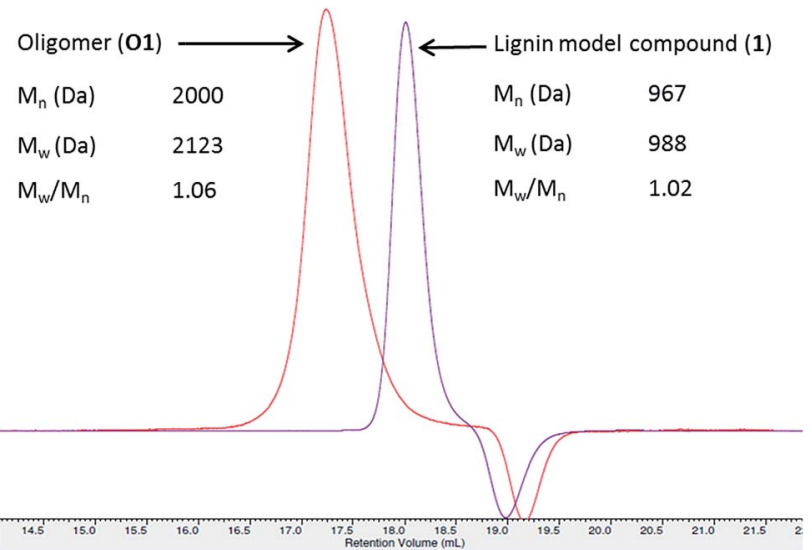

Fig. 1 GPC of oligomers (O1). GPC lignin model compound is given for comparison.

POL laccases did not initiate any oligomerisation or oxidative cleavage, ${ }^{22}$ indicating the specificity of laccase towards the phenolic substrates in the formation of phenoxy radicals that is crucial for subsequent oligomerisation. The reduction in concentration of laccase from 20 units per $\mathrm{mL}$ to 2 units per $\mathrm{mL}$ did not affect the molecular weight distribution of the oligomer formed $\left(M_{\mathrm{n}}=2120 \mathrm{Da} ; M_{\mathrm{w}}=2170 \mathrm{Da} ; M_{\mathrm{w}} / M_{\mathrm{n}}=1.0\right.$, Fig. S2, ESI $\left.\dagger\right)$. However, the initial rate of disappearance of $\mathbf{1}$ was found to be approximately 5 fold slower $\left(t_{1 / 2}=34.9 \mathrm{~min}\right.$, Fig. S3, ESI $\dagger$ ).

To gain understanding on the progress of the oxidation reaction, the reaction mixture was analysed by high performance liquid chromatography equipped with mass spectroscopy (LC-MS)

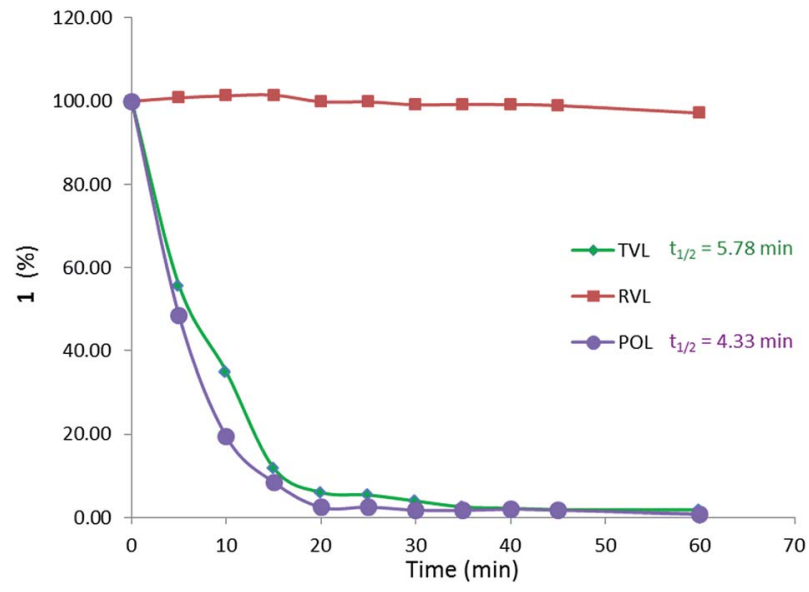

Fig. 3 Comparison of initial reactivity of three different laccases.

after quenching the reaction with sodium azide at regular intervals. The percentage of unreacted compound 1 was quantified using 9-acetylphenanthrene as an internal standard. The initial reaction progress for the oxidation of $\mathbf{1}$ with laccases TVL, POL and RVL is presented in Fig. 3. The amount of $\mathbf{1}$ decreased dramatically upon treatment with TVL and POL, while RVL did not show any noticeable activity. The higher activity of TVL and POL could be attributed respectively to their higher redox potentials $(790 \mathrm{mV}$ and $650 \mathrm{mV})$ than that of RVL $(430 \mathrm{mV})$. The HPLC chromatograms obtained for the reaction progress of $\mathbf{1}$ with TVL is presented in Fig. 2. Analysis of two new major peaks appeared (Fig. 2) at $25.2 \mathrm{~min}$ and $26.4 \mathrm{~min}$ by LC-MS indicated the mass of the

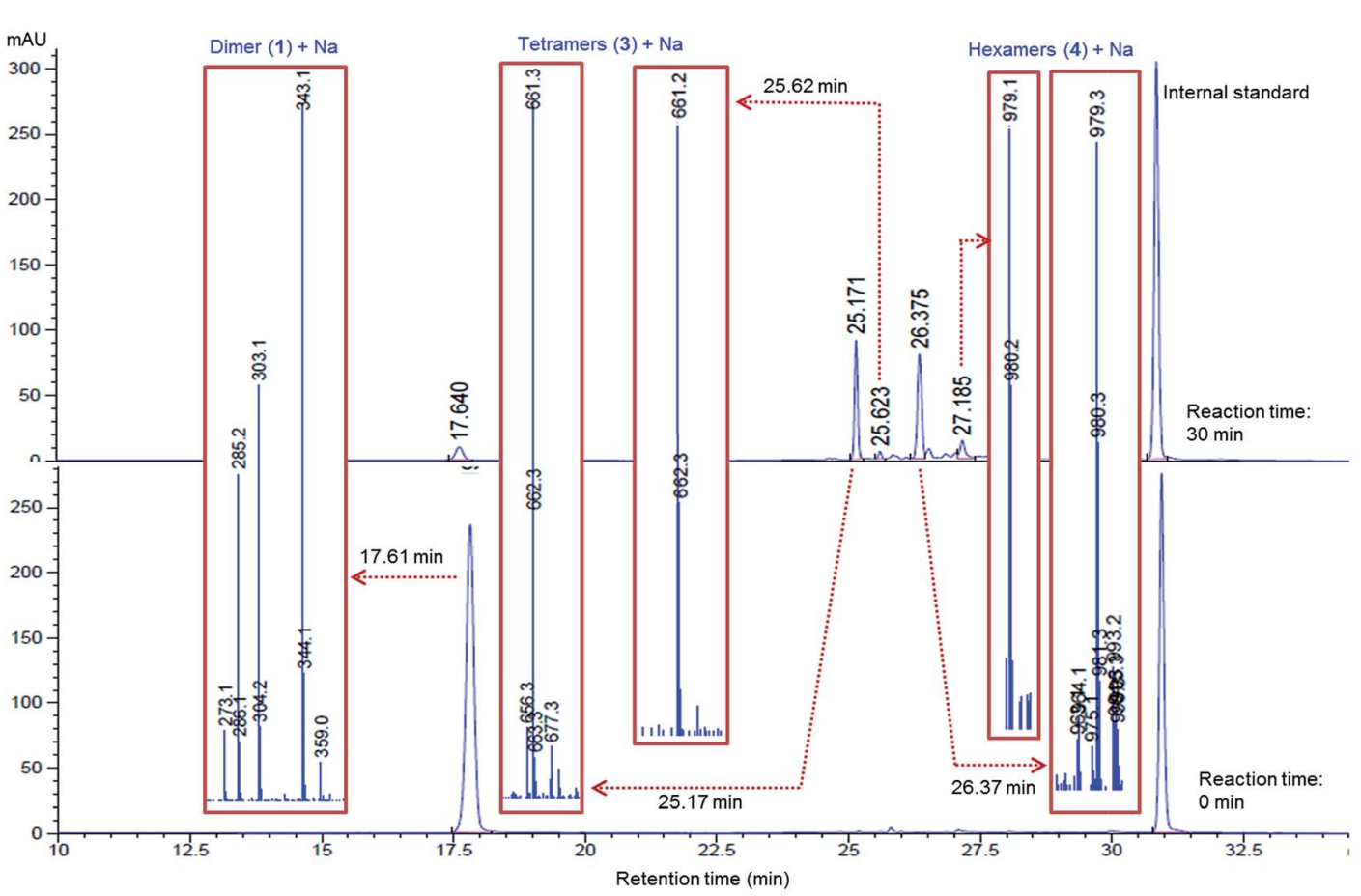

Fig. 2 LC-MS traces of laccase-catalysed oxidation of 1 at reaction times 0 min and 30 min. 9-Acetylphenanthrene was used as an internal standard for quantification. Mass obtained for the major and minor peaks are indicated. LC-MS traces at regular time intervals are depicted in ESI (Fig. S4†). 
tetramer (3, 661.3 $\mathrm{Da}\left(\mathrm{M}^{+}+\mathrm{Na}\right)$, Fig. S5, ESI $\left.\dagger\right)$ and the hexamer (4, 979.3 $\mathrm{Da}\left(\mathrm{M}^{+}+\mathrm{Na}\right)$, Fig. $\left.\mathrm{S} 7, \mathrm{ESI} \dagger\right)$ respectively. As the reaction proceeded, the concentration of $\mathbf{1}$ decreased progressively and the formation of 3 and 4 (Fig. 2) were found to be enriched. The detection of 4 (Fig. 2) by LC-MS suggested that the oligomerisation likely took place by a step-wise association of $\mathbf{1}$ to 3 . Otherwise, the self-coupling of 3 would lead to the formation of octamer directly without the formation of the hexamer 4 (Fig. 2). In contrast to the T. hirsuta laccase catalysed polymerisation of $\mathbf{1}^{\mathbf{2 0}}$ we did not observe the formation of any low molecular weight monomeric products as evidenced by LC-MS. The results indicated that laccase promoted the oligomerisation of $\mathbf{1}$ directly rather than depolymerisation of the dimeric or higher molecular weight products into monomeric products followed by re-polymerisation. The minor peak appeared at $25.6 \mathrm{~min}$ (Fig. 2) exhibited the mass value of 3 (661.2 $\mathrm{Da}, \mathrm{M}^{+}+\mathrm{Na}$, Fig. S6, ESI $\dagger$ ), indicating possible formation of diastereomeric isomers of tetramer 3 . The bond rotation of newly formed aryl-aryl bond ( $c f$. below, 3C, Fig. 4) is likely restricted due to highly substituted nature of lignin model compound (1) that resulted in the development of $R$ - and $S$ - diastereoisomers. More possibilities could be anticipated while the next molecule of $\mathbf{1}$ couple with 3C. Consequently, analysis of peak at $27.19 \mathrm{~min}$ (Fig. 2) by LC-MS indicated the mass value of hexamer 4 (979.1 Da, $\mathrm{M}^{+}+\mathrm{Na}$, Fig. S8, ESI $\dagger$ ). The appearance of minor peaks at $25.6 \mathrm{~min}$ and $27.19 \mathrm{~min}$, might also be due to the formation of tetramers and hexamers with different linkages, although DFT calculation did not favour such possibilities ( $c f$. below).

The formation of a phenoxy radical by one electron oxidation with concomitant reduction of oxygen to water by laccase is well known. ${ }^{23}$ The phenolic radical $\left(\mathbf{1 R}_{\mathbf{1}}\right)$ could undergo resonance and consequently various radical couplings are possible (Scheme 2). Simple oxidation of primary $\left(\mathrm{C}_{\gamma}\right)$ and secondary alcohol $\left(\mathrm{C}_{\alpha}\right)$ could also be possible ${ }^{22}$ under the present oxidative conditions (Scheme 2). However, we did not observe any detectable amount of $\mathrm{C}_{\alpha}$ and/or $\mathrm{C}_{\gamma}$ oxidised products under these conditions. In order to isolate the product that is being formed at the initial stage of the oligomerisation, the reaction was carried out with a lower concentration of laccase ( 2 units per $\mathrm{mL}) .{ }^{24}$ After $30 \mathrm{~min}$, the reaction was quenched with an aqueous solution of $\mathrm{NaN}_{3}$. LC-MS analysis indicated the presence of the tetramer (3) predominantly $(\sim 50 \%)$ together with compound $\mathbf{1}$ and other higher molecular weight oligomers. Tetramer (3) was separated from the other oligomers and compound $\mathbf{1}$ by semi-preparative thin layer chromatography (TLC) using 10\% dichloromethane in hexane. The observed mass value of $661.39(\mathrm{M}+\mathrm{Na})$ by ESI mass spectroscopy indicated the isolation of tetramer 3. For the isolation of hexamer 4 , the reaction was carried out with 20 units per $\mathrm{mL}$ of laccase and the reaction was quenched after $1 \mathrm{~h}$. Isolation of hexamer was carried out by semi preparative HPLC and confirmed by mass $(\mathrm{m} / \mathrm{z}, 979.60, \mathrm{M}+\mathrm{Na})$ analysis.

The linkage present in 3 was established by ${ }^{1} \mathrm{H},{ }^{13} \mathrm{C}$ and $2 \mathrm{D}$ NMR spectroscopy. The ${ }^{1} \mathrm{H}$ and ${ }^{13} \mathrm{C}$ NMR spectra were measured in deuterated acetone- $\mathrm{D}_{6}$ (Fig. S9-S12, ESI $\dagger$ ) and the following observations and interpretations were made. (i) The presence of phenolic $\mathrm{OH}(\delta, 7.39 \mathrm{ppm}), \mathrm{C}_{\alpha}-\mathrm{OH}(\delta, 4.51 \mathrm{ppm})$ and $\mathrm{C}_{\gamma}-\mathrm{OH}(\delta$, $3.69 \mathrm{ppm}$ ) groups observed in deuterated acetone, which ruled out the possibility of dimer formation through $\mathrm{C}-\mathrm{O}$ or $\mathrm{O}-\mathrm{O}$
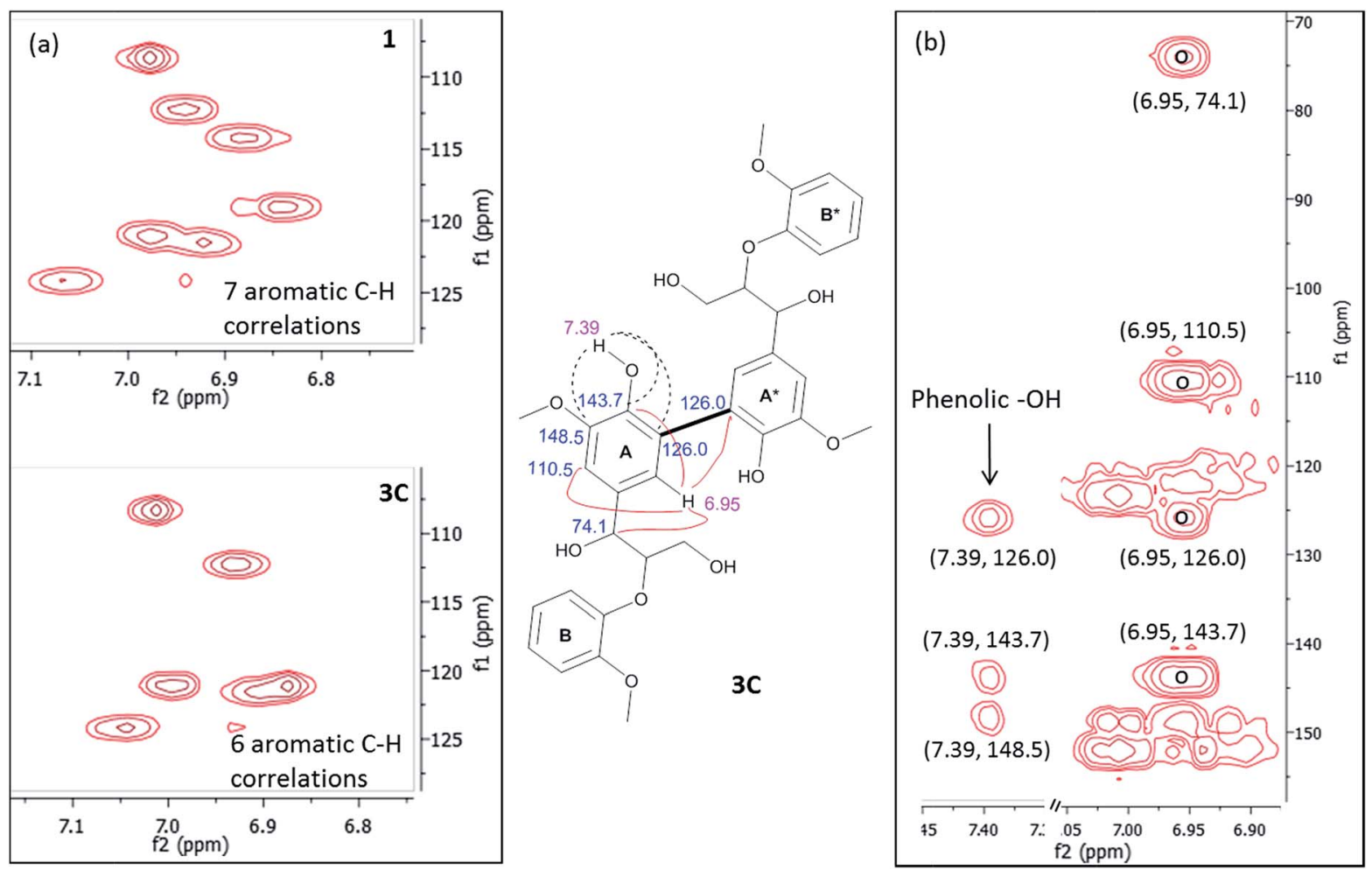

Fig. 4 (a) HSQC correlations of aromatic region of compounds 1 and 3C. (b) Important HMBC correlations present in compound 3C. 


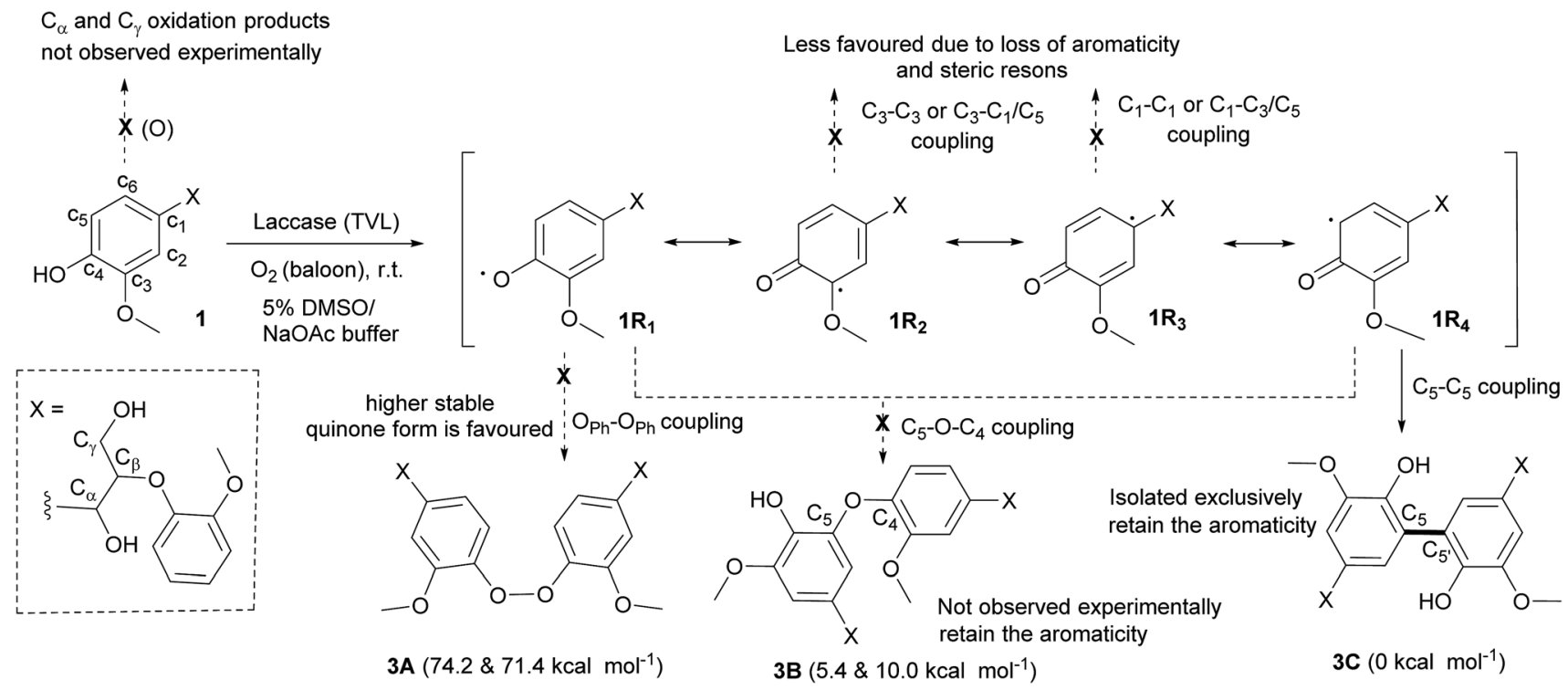

Scheme 2 Laccase-catalysed oxidative dimerization of 1. Radical formation and their different coupling possibilities are shown. The more favoured structure $3 \mathrm{C}$ is shown. The protonation and re-aromatization sequence are not presented for clarity. Relative free energies were calculated in gas phase and water by DFT and are given respectively within parentheses.

linkages; (ii) the observation of only one set of signals for $\mathrm{C}_{\alpha}-\mathrm{H}$ $(\delta, 4.93 \mathrm{ppm}), \mathrm{C}_{\beta}-\mathrm{H}(\delta, 4.33 \mathrm{ppm}), \mathrm{C}_{\gamma}-\mathrm{H}(\delta, 3.76$ and $3.76 \mathrm{ppm})$ and methoxy $(\delta, 3.79$ and $3.86 \mathrm{ppm})$ protons indicated that the tetramer formed from compound $\mathbf{1}$ is $\mathrm{C}_{2}$-symmetric; (iii) Attached Proton Test (APT) experiment in ${ }^{13} \mathrm{C}$ spectrum, the number of quaternary carbons in the aromatic region was increased while the number of aromatic $\mathrm{CH}$ carbons decreased compared to the spectrum of compound 1 (Fig. S13, ESI $\dagger$ ). All the above information indicated the possibility of a $\mathrm{C}_{2}$-symmetric molecule with a linkage through the aromatic carbons. The above fact was supported by the observation of only six aromatic $\mathrm{C}-\mathrm{H}$ correlations in the heteronuclear single quantum coherence (HSQC) spectra compared to the seven $\mathrm{C}-\mathrm{H}$ correlations found for compound $\mathbf{1}$ (Fig. 4a). The structure of tetramer $\mathbf{3 C}$ was finally confirmed by the heteronuclear multiple bond correlation (HMBC) spectrum (Fig. 4b). The phenolic -OH group showed both $J_{2}$ and $J_{3}$ correlations with three quaternary carbon atoms with $\delta(\mathrm{ppm})$ values $148.5,143.7$ and 126.0, which indicated the formation of a new bond at the $\mathrm{C}_{5}$ position of 'ring $\mathrm{A}$ ' of compound 1 . The proton assigned to one of the aromatic protons of 'ring A' at $\delta, 6.95 \mathrm{ppm}$ showed strong $\mathrm{HMBC}\left(J_{3}\right)$ correlations with four different carbons as indicated in Fig. $4 \mathrm{~b}$. The $J_{3}$ correlation of the proton $(\delta, 6.95$ $\mathrm{ppm})$ at 'ring $\mathrm{A}^{\prime}$ ' to the carbon (126.0 ppm) of 'ring $\mathrm{A}^{*}$ ' indicated that both rings are connected through a $\mathrm{C}_{5}-\mathrm{C}_{5^{\prime}}$ linkage. Based on the above rationale, the structure of the tetramer was confirmed as 3C (Fig. 4). To our knowledge, the complete NMR interpretation for the tetramer $3 \mathrm{C}$ is reported for the first time. ${ }^{25}$

The exclusive formation of $\mathbf{3 C}$ under the experimental conditions was supported with results obtained by DFT studies. The relative free energies of hypothetically favoured products that are being formed through linkages $\mathrm{C}_{5}-\mathrm{C}_{5^{\prime}}(3 \mathrm{C})$ and $\mathrm{C}_{5}-\mathrm{O}-$ $\mathrm{C}_{4}$ (3B) were calculated. The formation of $3 \mathrm{C}$ was found to be more favoured by $5.4 \mathrm{kcal} \mathrm{mol}^{-1}$ than that of 3B. Solvation with water was found to destabilize 3B further by $4.6 \mathrm{kcal} \mathrm{mol}^{-1}$, indicating the possible role of hydrogen bonding in the formation of $\mathrm{C}_{5}-\mathrm{C}_{5^{\prime}}$ linkage. DFT calculation for the formation $3 \mathbf{A}$ in gas phase $\left(74.2 \mathrm{kcal} \mathrm{mol}^{-1}\right)$ and in water $\left(71.4 \mathrm{kcal} \mathrm{mol}^{-1}\right)$ indicated that the $\mathrm{O}-\mathrm{O}$ linkage would be highly unfavourable. The observations could be related to $5-5^{\prime}$ biphenyl linkages present in lignin. In the biosynthesis of lignin, the more stable biphenyl linkages $\left(115-118 \mathrm{kcal} \mathrm{mol}^{-1}\right)^{26}$ might be formed initially by the oxidative polymerisation of $p$-coumaryl, coniferyl and sinapyl alcohols.

NMR spectra of the hexamer 4 in acetone- $\mathrm{D}_{6}$ and chloroformD showed a complex unresolved spectral pattern, possibly due to the existence of hexamers with different linkages that were not separable under the HPLC conditions. Based on the limited experimental details (mass, $m / z=979.60, \mathrm{M}+\mathrm{Na}$ ) available for the hexamers, we envision that calculating the free energies of most possible structures would help to identify the linkages present in the hexamer. In fact, in the case of the tetramer (3C), the prediction by DFT is in good agreement with the experimentally observed product. After the initial formation of 3, radicals originating from both $\mathbf{1}$ and $\mathbf{3}$ could possibly be present in the reaction mixture. The phenoxy radical of tetramer $\left(\mathbf{3} \mathbf{R}_{\mathbf{1}}\right)$ undergoes delocalisation as indicated in the Scheme 3. The potential transition states that are originated from the radicals centred at $\mathrm{C}_{1}, \mathrm{C}_{3}$ and $\mathrm{C}_{5}$ on the aromatic 'ring $\mathrm{A}$ ' of 3 are not taken into consideration, as the dimerization through those carbons ultimately leads to formation of the less favoured dearomatized product. In the LC-MS analysis, we did not observe significant formation (Fig. 2) of octamers that would possibly be formed by homo or hetero radical coupling of $\mathbf{3 R}_{\mathbf{2}}$ and/or $3 \mathbf{R}_{3}$. Thus, based on the above rational assumptions and understanding of radical chemistry, the five most possible modes of linkages for the hexamers were considered for the DFT 

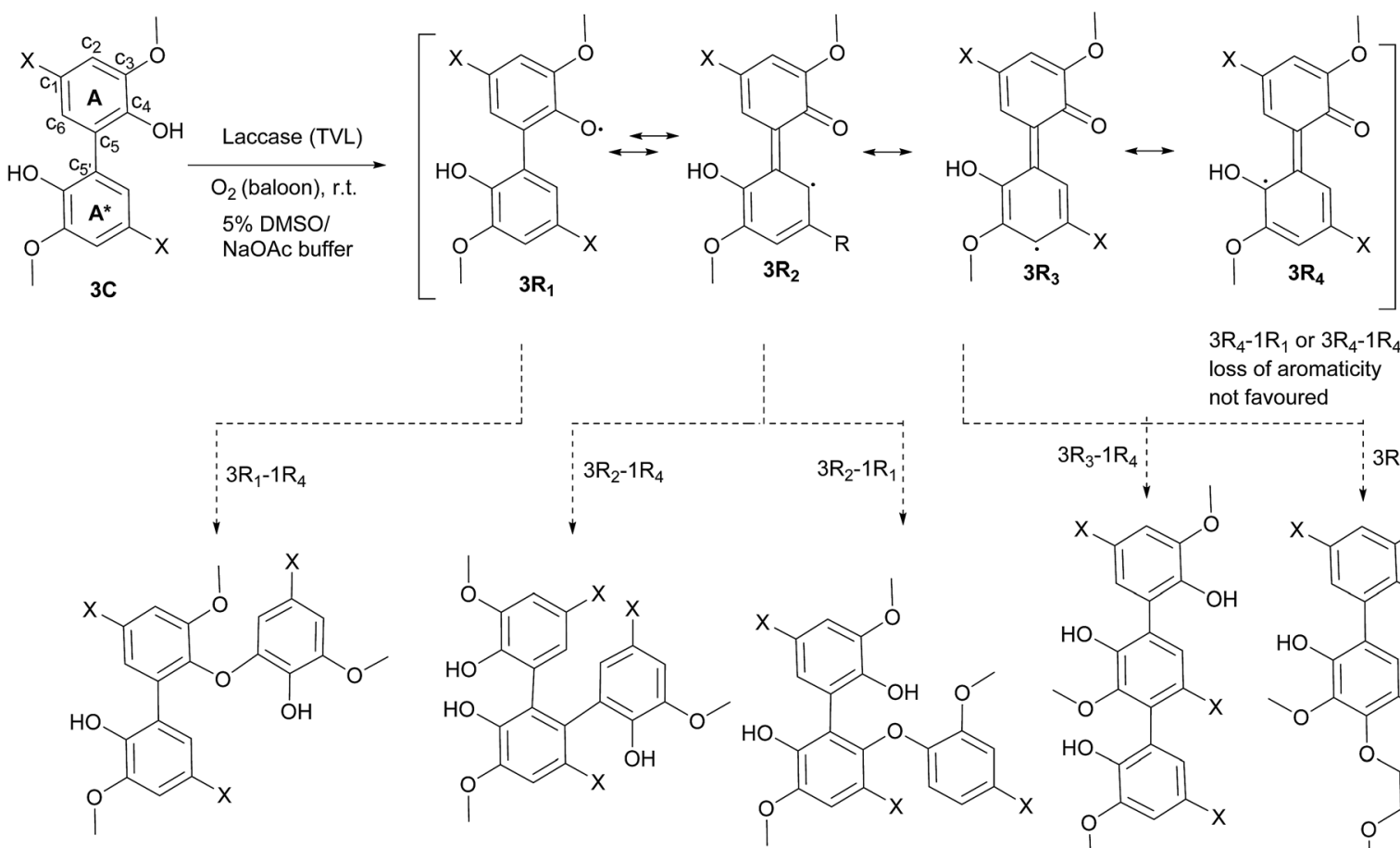

4A $\left(4.1 \& 4.2 \mathrm{Kcal} \mathrm{mol}^{-1}\right)$
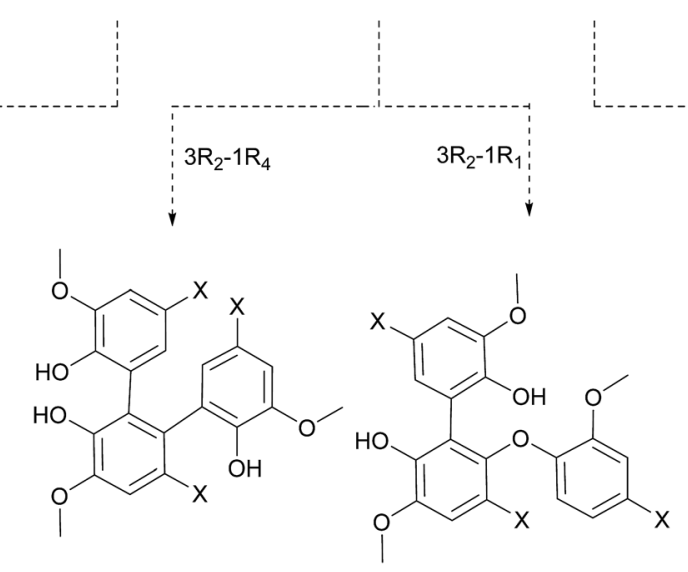<smiles>[X]c1cc(OC)c(O)c(-c2c(O)c(OC)cc([X])c2-c2c([X])cc([X])c(O)c2O)c1</smiles>

4B $\left(0 \mathrm{Kcal} \mathrm{mol}^{-1}\right)$<smiles>[X]c1ccc(Oc2c([X])cc(OC)c(O)c2-c2c([X])cc([X])c(OC)c2O)c(OC)c1</smiles><smiles>[X]c1cc(OC)c(O)c(-c2c([X])cc([Y])c(OC)c2-c2cc([X])cc(OC)c2O)c1</smiles>

$3 R_{4}-1 R_{1}$ or $3 R_{4}-1 R_{4}$ oss of aromaticity not favoured<smiles>[R17][Y9]([H])=CC</smiles>
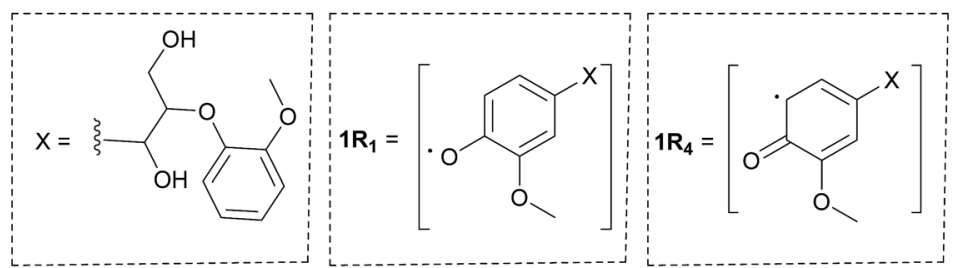

Scheme 3 Proposed pathways for the formation of hexamers $(4 \mathrm{~A}-4 \mathrm{E})$. The unflavoured structures originated from radical resonances at $C_{3}, C_{1}$ and $C_{5}$ carbons of 'ring $A^{\prime}$ are not presented; relative free energies were calculated in gas phase and water by DFT and are given respectively within parentheses.

calculation (4A-4E, Scheme 3). Relative free energy changes (Fig. 5) for hexamers $\mathbf{4 A - 4 E}$ were compared to the most stable product. The thermodynamic stability of the hexamers follows the order $4 \mathbf{B}\left(0 \mathrm{kcal} \mathrm{mol}^{-1}\right)>\mathbf{4 A}\left(4.1 \mathrm{kcal} \mathrm{mol}^{-1}\right)>4 \mathbf{D}(5.8 \mathrm{kcal}$ $\left.\mathrm{mol}^{-1}\right)>4 \mathrm{C}\left(13.7 \mathrm{kcal} \mathrm{mol}^{-1}\right)>4 \mathrm{E}\left(29.3 \mathrm{kcal} \mathrm{mol}^{-1}\right)$. We propose that the hexamer might be formed through a $\mathrm{C}-\mathrm{C}$ linkage as illustrated in hexamer 4B. However, the difference in energy

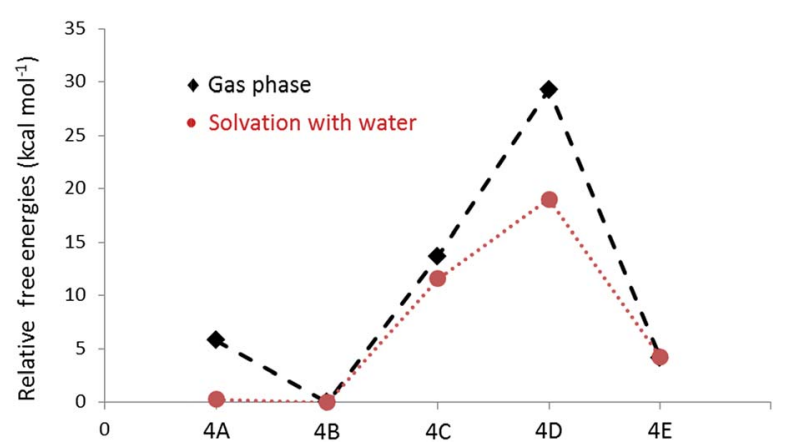

Fig. 5 Relative free energy changes for the formation of hexamers with different linkages in gas phase and under solvation. between $4 \mathrm{~A} v s .4 \mathrm{~B}\left(4.1 \mathrm{kcal} \mathrm{mol}^{-1}\right)$ and $4 \mathrm{~A} v s .4 \mathrm{D}\left(1.7 \mathrm{kcal} \mathrm{mol}^{-1}\right)$ is not remarkably different. DFT calculation of $\mathbf{4 A - 4 E}$ was performed using water as a solvent. The observed data indicated that solvation significantly enhance the overall stability of product formation (Fig. 5). In the oxidation of vanillyl alcohol, the formation of a thermodynamically less stable $\mathrm{C}_{5}-\mathrm{C}_{5^{\prime}}$ (by $5.6 \mathrm{kcal}$ $\mathrm{mol}^{-1}$ ) dimer was observed ${ }^{16}$ over the most stable vanillin due to hydrogen bonding present in the former.

\section{Experimental}

\section{Chemicals and materials}

Lignin model compounds 1-(4-hydroxy-3-methoxyphenyl)2(2-methoxyphenoxy)-propane-1,3-diol (1) and 1-(3,4dimethoxyphenyl)-2(2-methoxyphenoxy)-propane-1,3-diol (2) were purchased from TCI and Azatech chemicals respectively and used as such for all the experiments. Trametes versicolor laccase (TVL), Rhus vernicifera laccase (RVL) and Pleurotus ostreatus laccase (POL) were purchased from Aldrich and used as such for enzymatic reactions. 
General procedure for laccase catalysed oligomerisation. Dimeric lignin model compounds $(0.30 \mathrm{mmol})$ were dissolved in dimethylsulphoxide $(0.50 \mathrm{~mL}, 10 \%$ with respect to buffer $)$ and $5 \mathrm{~mL}$ of sodium acetate buffer ( $\mathrm{pH}$ 5.2) added. The reaction mixture was purged with $\mathrm{O}_{2}$ for $5 \mathrm{~min}$. A solution of laccase (220 units per $\mathrm{mL}$ ) was then added followed by stirring at $25{ }^{\circ} \mathrm{C}$ under $\mathrm{O}_{2}$ (balloon) for 3 hours. The pale brown precipitate formed was collected by centrifugation and dried under vacuum at $50{ }^{\circ} \mathrm{C}$ for 24 hours. Yield: $92 \mathrm{wt} \%$. The intermediate samples $(400 \mu \mathrm{L})$ for HPLC analysis were taken by quenching $400 \mu \mathrm{L}$ of the reaction mixture with $4 \%$ aqueous solution $(400 \mu \mathrm{L})$ of sodium azide. Known amount of 9-acetylphenanthrene was added for estimating the amount of unreacted compound 1 present in the reaction mixture. HPLC analysis: Jupiter $4 \mathrm{u}$ Proteo 90A $(150 \times 4.5 \mathrm{~mm}) ; \mathrm{H}_{2} \mathrm{O}\left(0.1 \% \mathrm{CF}_{3} \mathrm{COOH}\right): \mathrm{CH}_{3} \mathrm{CN}$ (0.1\% $\left.\mathrm{CF}_{3} \mathrm{COOH}\right)$, gradient flow, $90 \% \mathrm{H}_{2} \mathrm{O}$ to $50 \% \mathrm{H}_{2} \mathrm{O}(25 \mathrm{~min})$, $50 \% \mathrm{H}_{2} \mathrm{O}$ to $30 \% \mathrm{H}_{2} \mathrm{O}$ (30 min); flow rate, $0.5 \mathrm{~mL} \mathrm{~min}^{-1} ; 25^{\circ} \mathrm{C}$; $254 \mathrm{~nm} . t_{\mathrm{r}}($ dimer $)=17.7 \mathrm{~min}, t_{\mathrm{r}}($ tetramer $)=25.1 \mathrm{~min}, t_{\mathrm{r}}$ (tetramer) $=26.4 \mathrm{~min}$.

Isolation of tetramer (3C). Dimeric lignin model compound $1(0.10 \mathrm{~g}, 0.31 \mathrm{mmol})$ was dissolved in dimethylsulphoxide (0.5 $\mathrm{mL}, 10 \%$ with respect to buffer) and $5 \mathrm{~mL}$ of sodium acetate buffer ( $\mathrm{pH}$ 5.2) was added. After purging the reaction mixture with $\mathrm{O}_{2}$ for $5 \mathrm{~min}$, a solution of laccase ( 2 units per $\mathrm{mL}$ ) was added, stirred for $35 \mathrm{~min}$ at $25{ }^{\circ} \mathrm{C}$ and quenched with $4 \%$ aqueous solution of $\mathrm{NaN}_{3}$. The reaction mixture was extracted with ethyl acetate $(3 \times 10 \mathrm{~mL})$, dried over sodium sulphate and concentrated. Compound 3 was obtained by semi-preparative TLC using $10 \%$ dichloromethane in hexanes. The collected product was analysed by NMR and mass spectroscopy. Yield: $24.2 \mathrm{mg}(24 \%) .{ }^{1} \mathrm{H}$ NMR (acetone- $\mathrm{D}_{6}, 400 \mathrm{MHz}$ ), $\delta=7.39$ (br s, $2 \mathrm{H}$, phenolic OHs), 7.12 (t, $J=2.0 \mathrm{~Hz}, 2 \mathrm{H}, \mathrm{ArH}), 6.99$ (dd, $J=7.9$, $1.5 \mathrm{~Hz}, 2 \mathrm{H}, \mathrm{ArH}), 6.96-6.89(\mathrm{~m}, 6 \mathrm{H}, \mathrm{ArH}), 6.84-6.80(\mathrm{~m}, 2 \mathrm{H}$, $\mathrm{ArH}), 4.93\left(\mathrm{t}, J=5.0 \mathrm{~Hz}, 2 \mathrm{H}, \mathrm{C}_{\alpha}-\mathrm{H}\right), 4.51(\mathrm{dd}, J=4.5,1.5 \mathrm{~Hz}, 2 \mathrm{H}$, $\left.\mathrm{C}_{\alpha}-\mathrm{OH}\right), 4.34\left(\mathrm{dd}, J=5.5,1.5 \mathrm{~Hz}, 2 \mathrm{H}, \mathrm{C}_{\beta}-\mathrm{OH}\right), 4.34(\mathrm{dd}, J=5.5$, $\left.1.5 \mathrm{~Hz}, 2 \mathrm{H}, \mathrm{C}_{\beta}-\mathrm{OH}\right), 3.86-3.83\left(\mathrm{~m}, 8 \mathrm{H}, \mathrm{C}_{\gamma}-\mathrm{H}, \mathrm{OCH}_{3}\right), 3.79-3.74$ $\left(\mathrm{m}, 8 \mathrm{H}, \mathrm{OCH}_{3}, \mathrm{C}_{\gamma}-\mathrm{H}\right), 3.69\left(\mathrm{t}, 2 \mathrm{H}, J=6.0 \mathrm{~Hz}, \mathrm{C}_{\gamma}-\mathrm{OH}\right) ;{ }^{13} \mathrm{C} \mathrm{NMR}$ (acetone- $\left.\mathrm{D}_{6}, 100 \mathrm{MHz}\right) \delta=152.1,149.2,148.4,143.7,133.9$, 133.9, 126.0, 123.4, 122.9, 121.9, 119.9, 113.7, 110.5, 86.8, 74.1, 61.9, 56.5, 56.4, 29.8; LR-MS (ESI): $m / z$ calcd for $\mathrm{C}_{34} \mathrm{H}_{38} \mathrm{O}_{12}$ : 638.24. Found: $661.40(\mathrm{M}+\mathrm{Na})^{+}$.

Computational methods. Gas phase calculations were performed using the M06-2X functional ${ }^{27}$ with the $6-31 \mathrm{G}(\mathrm{d})$ basis set. Harmonic frequency calculations were carried out to ensure the nature of the local minima as well as estimating the Gibbs free energies at $298 \mathrm{~K}$. Water calculations were performed using the $\mathrm{SMD}^{28}$ continuum solvation model. All DFT calculations were carried out using the Gaussian 09 program suite. ${ }^{29}$

\section{Conclusions}

The initial progress of the laccase-catalysed oxidative oligomerisation reaction for $\beta-\mathrm{O}-4$ linked dimeric model lignin compounds was carefully studied. The redox potential and concentration of laccase were found to be important in the formation of products. The initial oligomerisation products were isolated successfully and the mode of linkages was established. The current study indicated that the oligomerisation of $\beta-\mathrm{O}-4$ linked lignin model compound led to the formation of a tetramer through $\mathrm{C}-\mathrm{C}$ linkages exclusively similar to $\mathrm{C}_{5}{ }^{-}$ $\mathrm{C}_{5^{\prime}}$ linkages present in the native lignin. The initial stage of oligomerisation process was found to be governed by the thermodynamic stability of products although different linkages are possible for the radicals to couple. The current understanding on the oligomerisation of dimeric lignin model compounds would pave the way to make important decisions in the use of laccase in the oxidative cleavage of lignin. Laccase has been considered ${ }^{\mathbf{3 0}}$ as one of the potential enzymes for the depolymerisation of lignin. Our current studies indicate that oligomerisation by oxidative coupling is more preferred over the oxidative cleavages even in the case of readily cleavable $\beta-O-4$ linkages $\left(54-69 \mathrm{kcal} \mathrm{mol}^{-1}\right){ }^{26}$ Although the laccase has a potential to cleave lignin or lignin model compounds in the presence of mediators ${ }^{22}$ to phenolcontaining monomers or dimers, these phenolic compounds may undergo re-polymerisation more readily under similar reaction conditions. As a result, the thermodynamically more stable oligomers or polymers will be formed at the end of the overall process. Meyer et al. ${ }^{26}$ reviewed laccase-catalysed bond cleavage in lignin and made similar conclusions earlier. Thus, laccase alone would not be able to cleave lignin under oxidative conditions. Altering the redox potential of laccase by mutation in order to facilitate the oxidation of non-phenolic hydroxyl groups, may help lignin depolymerisation in the presence of suitable redox mediators. The current observations might help to exploit the readily accessible stable laccase enzymes for aromatic $\mathrm{C}-\mathrm{C}$ coupling, which is currently under exploration in our laboratory.

\section{Acknowledgements}

The work was funded by Agency for Science, Technology and Research (A*STAR), Singapore under the 'Biomass to Chemicals' programme. Mr Zhao Wenguang and Dr Saravanan Gowrisankar are acknowledged for GPC analysis and HPLC calibration respectively. Dr Michael B. Sullivan acknowledges A*STAR Computational Resource Centre (ACRC), Singapore for the use of high performance computing facilities for the DFT computations performed in this work.

\section{Notes and references}

1 (a) C. Xu, R. Arneil, D. Arancon, J. Labidid and R. Luque, Chem. Soc. Rev., 2014, 43, 7485-7500; (b) R. Ma, Y. Xu and X. Zhang, ChemSusChem, 2015, 8, 24-51; (c) R. Katahira, A. Mittal, K. McKinney, P. N. Ciesielski, B. S. Donohoe, S. K. Black, D. K. Johnson, M. J. Biddy and G. T. Beckham, ACS Sustainable Chem. Eng., 2014, 2, 1364-1376.

2 (a) J. Zakzeski, P. C. A. Bruijnincx, A. L. Jongerius and B. M. Weckhuysen, Chem. Rev., 2010, 110, 3552-3599; (b) C. Amen-Chen, H. Pakdel and C. Roy, Bioresour. Technol., 2001, 79, 277-299.

3 C. W. Dence and S. Y. Lin, in Methods in Lignin Chemistry, ed. S. Y. Lin and C. W. Dence, Springer-Verlang, Berlin, Heidelberg, 1992, pp. 3-19. 
4 (a) J. M. Humphreys and C. Chapple, Curr. Opin. Plant Biol., 2002, 5, 224-229; J. F. D. Dean and K. E. L. Eriksson, Holzforschung, 1994, 48, 21-33. (b) D. M. O'Malley, R. Whetten, W. Bao, C. L. Chen and R. Sederoff, Plant J., 1993, 4, 751-757.

5 (a) J. R. Jeon, P. Baldrian, K. Murugesan and Y. S. Chang, Micobial Biotech., 2012, 5, 318-332; (b) N. Mita, S. Tawaki, H. Uyama and S. Kobayashi, Macromol. Biosci., 2003, 3, 253-257; (c) A. M. Mayer and R. C. Staples, Phytochemistry, 2002, 60, 551-565; (d) L. Gianfreda, F. Xu and J. M. Bollag, Biochem. J., 1999, 3, 1-25.

6 (a) X. Sun, R. Ba, Y. Zhang, Q. Wang, X. Fan, J. Yuan, L. Cui and P. Wang, Appl. Biochem. Biotechnol., 2013, 171, 16731680; (b) R. Ikeda, J. Sugihara, H. Uyama and S. Kobayashi, Macromolecules, 1996, 29, 8702-8705.

7 N. Aktas, G. Kibarer and A. Tanyolac, J. Chem. Technol. Biotechnol., 2000, 75, 840-846.

8 T. Tanaka, M. Takahashi, H. Hagino, S. I. Nudejima, H. Usui, T. Fujii and M. Taniguchi, Chem. Engg. Sci., 2010, 65, 569573.

9 M. Lahtinen, K. Kruus, H. Boer, M. Kemell, M. Andberg, L. Viikari and J. Sipila, J. Mol. Catal. B: Enzym., 2009, 57, 204-210.

10 L. Pistone, G. Ottolina, S. De, A. A. Romero, L. O. Martins and R. Luque, ChemSusChem, 2016, 9, 756-762.

11 (a) D. Kai, M. J. Tan, P. L. Chee, Y. K. Chua, Y. L. Yap and X. J. Loh, Green Chem., 2016, 18, 1175-1200; (b) V. K. Thakur, M. K. Thakur, P. Raghavan and M. R. Kessler, ACS Sustainable Chem. Eng., 2014, 2, 10721092.

12 Y. Qian, X. Q. Qiu and S. P. Zhu, Green Chem., 2015, 17, 320324.

13 (a) K. Crouvisier-Urion, P. R. Bodart, P. Winckler, J. Raya, R. D. Gougeon, P. Cayot, S. Domenek, F. Debeaufort and T. Karbowiak, ACS Sustainable Chem. Eng., 2016, 4, 63716381; (b) D. Kai, Y. K. Chua, L. Jiang, C. Owh, S. Y. Chan and X. J. Loh, RSC Adv., 2016, 6, 86420-86427.

14 A. Hambardzumyan, L. Foulon, B. Chabbert and V. AguieBeghin, Biomacromolecules, 2012, 13, 4081-4088.

15 M. K. Chan, Q. Ye, Z. M. Png, H. N. Zeng, X. Wang and J. Xu, Waste Biomass Valorization, 2016, DOI: 10.1007/s12649-0169737-4.

16 M. Lahtinen, P. Heinonen, M. Oivanen, P. Karhunen, K. Kruus and J. Sipilä, Org. Biomol. Chem., 2013, 11, 54545464.

17 M. Lahtinen, K. Kruus, P. Heinonen and J. Sipila, J. Agric. Food Chem., 2009, 57, 8357-8365.

18 A. Llevot, E. Grau, S. Carlotti, S. Grelier and H. Cramail, J. Mol. Catal. B: Enzym., 2016, 125, 34-41.

19 M. A. Constantin, J. Conrad and U. Beifuss, Green Chem., 2012, 14, 2375-2379.

20 K. Rittstieg, A. Suurnäkki, T. Suortti, K. Kruus, G. M. Guebitz and J. Buchert, Enzyme Microb. Technol., 2002, 31, 403-410.

21 K. Rittstieg, A. Suurnäkki, T. Suortti, K. Kruus, G. M. Guebitz and J. Buchert, Biotechnol. Prog., 2003, 19, 1505-1509.

22 Oxidative cleavage of $\beta-\mathrm{O}-4$ containing dimeric model compounds could potentially be possible by the oxidation of $\mathrm{C}_{\alpha^{-}}$and $\mathrm{C}_{\gamma}$-hydroxyl groups, however in the presence of mediator systems. See. (a) R. Bourbonnais and M. G. Paice, FEBS Lett., 1990, 267, 99-102; (b) S. Kawai, M. Nakagawa and H. Ohashi, FEBS Lett., 1999, 446, 355-358; (c) S. Kawai, M. Nakagawa and H. Ohashi, Enzyme Microb. Technol, 2002, 30, 482-489; (d) H. Hirai, H. Shibata, S. Kawai and T. Nishida, FEMS Microbiol. Lett., 2006, 265, 56-59; (e) A. I. Canas and S. Camarero, Biotechnol. Adv., 2010, 28, 694-705; (f) C. Crestini, L. Jurasek and D. S. Argyropoulos, Chem. -Eur. J., 2003, 9, 5371-5378.

23 G. Carlo, M. Catherine, V. Raffaella, J. Claude and G. Patrizia, ChemBioChem, 2013, 14, 2500-2505.

24 We observed higher product distribution of 3 after $30 \mathrm{~min}$ of reaction time when 2 units per $\mathrm{mL}$ of TVL was used. While to get higher product distribution of 4, 20 units per $\mathrm{mL}$ of TVL was used for $1 \mathrm{~h}$ of reaction time.

25 To our knowledge, complete NMR data for 3C has not been reported. Incomplete $\mathrm{NMR}$ data was provided for the acetylated $\mathbf{3 C}$ in the literature without details on the assignments. (a) L. L. Landucci, S. A. Ralph and K. E. Hammel, Holzforschung, 1998, 52, 160-170; (b) K. Syrjänen and G. Brunow, J. Chem. Soc., Perkin Trans. 1, 1998, 3425-3429. It is practically harder to establish the linkages using the acetylated $\mathbf{3 C}$, as phenolic $-\mathrm{OH}$ group gives the strong basis for the identification of the $\mathrm{C5}_{-}-\mathrm{C5}^{\prime}$ linkage by HMBC NMR spectrum.

26 L. Munk, A. K. Sitarz, D. C. Kalyani, D. Mikkelsen and A. S. Meyer, Biotechnol. Adv., 2015, 33, 13-24.

27 (a) Y. Zhao and D. G. Truhlar, Theor. Chem. Acc., 2008, 120, 215-241; (b) Y. Zhao and D. G. Truhlar, Acc. Chem. Res., 2008, 41, 157-167.

28 A. V. Marenich, C. J. Cramer and D. G. Truhlar, J. Phys. Chem. $B, 2009,113,6378-6396$.

29 M. J. Frisch; G. W. Trucks; H. B. Schlegel; G. E. Scuseria; M. A. Robb; J. R. Cheeseman; G. Scalmani; V. Barone; B. Mennucci; G. A. Petersson; H. Nakatsuji; M. Caricato; X. Li; H. P. Hratchian; A. F. Izmaylov; J. Bloino; G. Zheng; J. L. Sonnenberg; M. Hada; M. Ehara; K. Toyota; R. Fukuda; J. Hasegawa; M. Ishida; T. Nakajima; Y. Honda; O. Kitao; H. Nakai; T. Vreven; J. A. Montgomery Jr; J. E. Peralta; F. Ogliaro; M. Bearpark; J. J. Heyd; E. Brothers; K. N. Kudin; V. N. Staroverov; R. Kobayashi; J. Normand; K. Raghavachari; A. Rendell; J. C. Burant; S. S. Iyengar; J. Tomasi; M. Cossi; N. Rega; M. J. Millam; M. Klene; J. E. Knox; J. B. Cross; V. Bakken; C. Adamo; J. Jaramillo; R. Gomperts; R. E. Stratmann; O. Yazyev; A. J. Austin; R. Cammi; C. Pomelli; J. W. Ochterski; R. L. Martin; K. Morokuma; V. G. Zakrzewski; G. A. Voth; P. Salvador; J. J. Dannenberg; S. Dapprich; A. D. Daniels; Ö. Farkas; J. B. Foresman; J. V. Ortiz; J. Cioslowski and D. J. Fox, Gaussian 09, Revision A.02, Gaussian, Inc., Wallingford CT, 2009.

30 (a) S. Majumdar, T. Lukk, J. O. Solbiati, S. Bauer, S. N. Nair, J. E. Cronan and J. A. Gerlt, Biochemistry, 2014, 53, 40474058; (b) H.-D. Youn, Y. C. Hah and S.-O. Kang, FEMS Microbiol. Lett., 1995, 132, 183-188; (c) C. Eggert, U. Temp and K. E. L. Eriksson, FEBS Lett., 1997, 407, 89-92. 